This is a pre-print. The article is published at https://doi.org/10.1177/1461444816662933

\title{
Uses and Gratifications factors for social media use in teaching: Instructors' perspectives
}

\author{
Anatoliy Gruzd \\ Ryerson University, Canada \\ Caroline Haythornthwaite \\ Syracuse University, USA \\ Drew Paulin \\ University of California, Berkeley, USA \\ Sarah Gilbert \\ University of British Columbia, Canada \\ Marc Esteve del Valle \\ Ryerson University, Canada
}

\begin{abstract}
This research was motivated by an interest in understanding how social media are applied in teaching in higher education. Data were collected using an online questionnaire, completed by 333 instructors in higher education, that asked about general social media use and specific use in teaching. Education and learning theories suggest three potential reasons for instructors to use social media in their teaching: (1) exposing students to practices, (2) extending the range of the learning environment, and (3) promoting learning through social interaction and collaboration. Answers to open-ended questions about how social media were used in teaching, and results of a factor analysis of coded results, revealed six distinct factors that align with these reasons for use: (1) facilitating student engagement, (2) instructor's organization for teaching, (3) engagement with outside resources, (4) enhancing student attention to content, (5) building communities of practice, and (6) resource discovery. These factors accord with a Uses and Gratifications perspective that depicts adopters as active media users choosing and shaping media use to meet their own needs. Results provide a more comprehensive picture of social media use than found in previous work, encompassing not only the array of media used but also the range of purposes associated with use of social media in contemporary teaching initiatives.
\end{abstract}

\section{Keywords}

Adoption of technology, educational technology, higher education, instructor experiences, social media, teaching, Uses and Gratifications

\section{Introduction}

The use of social media in teaching in higher education is growing, responding to increased use by students and in recognition of the potential for enhancing the teaching and learning experience. Such use capitalizes on the wider social networks reachable via social media while simultaneously meeting students where and how they live, that is, online, actively reading, posting, and sharing to an array of sites and applications that document life, support social interaction, and act as sites for resources. Estimates of social media use among university age students are high. An 
analysis of results from 27 US surveys by the Pew Internet and American Life project covering the years 2005-2015 shows widespread and rapid uptake in social media use, particularly among college age users (Perrin, 2015).

Given this growth in social media use, it is not surprising to find that university instructors are similarly actively using social media for personal and professional purposes and increasingly in teaching practices, and recording their experiences (e.g. Davis et al., 2015; Gammon and McGranahan, 2015; Manca and Ranieri, 2016; Veletsianos et al., 2013). Gruzd and Goertzen (2013) found that scholars, and in particular social scientists, are using social media to gather information, collaborate, network, and share information. In another study of academics, Lupton (2014) found that $97 \%$ of the 711 respondents to her survey used social media as part of their academic work for purposes such as personal network development, self-promotion, research, teaching, and support.

While these studies address overall use by academics, there are fewer studies addressing use for teaching. One major study is a survey of 8000 US faculty by Seaman and Tinti-Kane (2013). The study found that $70 \%$ of faculty use social media at least monthly for personal purposes and 55\% for professional purposes, with $41 \%$ using social media in teaching. The authors particularly note that sites used most frequently for teaching-blogs and wikis, podcasts - are quite different from those used for personal or professional use, where Facebook and LinkedIn are more frequently used.

Such findings about use and about particular and different use for personal, professional, and teaching purposes draw our attention to purposive adoption and adaptation of media to serve specific needs and underline the interest in this research in exploring not just what media are being used but also for what purposes they are used within the teaching context. A view of purposive media adoption accords with the theoretical perspective of the Uses and Gratifications $(\mathrm{U} \& \mathrm{G})$ framework which acknowledges media adopters as active decision makers, seeking, using, and applying media for their own purposes (Katz et al., 1973; Papacharissi, 2008; Shao, 2009). This framework orients inquiry about media use in teaching to the decisions that adopters make and the purposes these media serve. Moreover, it directs attention to the range of media that could be brought into use, rather than limiting inquiry to the media and teaching-support features supported by the institution (e.g. in learning management systems). Thus, our focus in this study is on the factors that drive decision-making for the introduction and sustained use of social media in teaching.

To explore the motivations and outcomes of use of social media in teaching, we designed a questionnaire to gather details on social media use by university-level instructors. Our goal was to gain as much detail as possible, within the constraints of a questionnaire, on individual use outside and inside the classroom, with an aim of understanding instructors' motivations and experience of using social media in their educational practice.

\section{Social media and learning}

This section addresses three theoretical reasons that emerge from education and learning theories and suggest why instructors may seek to introduce social media into their classes in support of teaching and learning. These are exposing students to practice; extending the learning environment; and promoting a social, collaborative approach to learning.

\section{Exposure to practice}

The first reason, that social media use exposes students to practice that reflects expected future work and communication settings, accords with ideas of experiential and social learning. This includes John Dewey's (18591952) emphasis on learning through "lived experiences," that is, connecting learning activities to the complexity of real-world practice and the many ways this can influence understanding (Bruce, 2009; Dewey, 1930); Bandura's (2001) social learning theory that holds that observing practice is also a way to gain knowledge even without participating; Lave and Wenger's (1991) ideas of legitimate peripheral participants learning the norms of social practice through observation; and e-learning perspectives that emphasize participation, engagement, and coconstruction of learning environments, learning how "to be" e-learners who know how to learn with others online and be active, engaged, and participatory learners who build knowledge on and through the Internet (Garrison and Anderson, 2003; Haythornthwaite and Andrews, 2011).

Studies of social media and teaching from these perspectives are limited, and where learning about practice is mentioned it is often about the difficulty or lack of support in learning how to use social media rather than use to enhance learning. Attention appears to be to the practice of being an e-learner or social media learning, and studies report more about learning the practices of the classroom than practice in the world. Bennett et al. (2012), in a study of six courses that each employed different types of social media in different ways, found that students struggled with using social media as they felt they did not receive enough institutional or instructional support on how to use the media. Similarly, Dahlstrom et al. (2013), in a survey of 113,035 undergraduate students from 14 countries about 
perceptions and use of technology in higher education, found that while students recognized the value of social media for learning, they also wanted guidance on how to make better use of the media in their studies.

Instructors are also found to be engaged in a process of becoming e-learning (or social media-learning) instructors. In the Bennett et al. (2012) study, most of the challenges appear to be due to a poor fit between the kind of task asked of students and its assessment. For example, in one course, students worked collaboratively on a wiki where individual authorship was de-emphasized, but their work was still assessed individually. In courses where individual contributions were publicly shared, students found social media of benefit because they were able to receive and view feedback from other students, broadening their educational experiences. Deriving such benefit, however, was not universal: where students commented on individually submitted blogs, feedback was uneven and less beneficial. Bennett et al. conclude that their study shows the difficulty in generalizing across instances due to differences across groups and social media technologies.

A number of studies point to the role of instructors in modeling effective social media use, a practice that can reflect both learning to be an effective e-learner and modeling real-world practices. Waldeck and Dougherty (2011) found that when students perceived that instructors used communication technologies effectively, they were more motivated to learn and experienced more positive learning outcomes. Imlawi et al. (2015) explored instructor credibility in association with use of social media and found that where instructors posted self-disclosing information and used humor, educational outcomes such as engagement were positively affected. While this again reflects instructor's modeling of practices, it may also be viewed as way of building trust and collaboration, discussed below.

These two studies (as well as others, for example, Hung and Yuen, 2010; Lampe et al., 2011) point to the importance of effective modeling and use of social media by faculty as vital for successful learning environments. While few studies directly address social media use to model non-university or workplace practice, as social media become workplace practice, successful modeling in the class provides experience with these forms of communication. The studies do, however, emphasize the leading role that faculty take in modeling practices, pointing out once again the need for "teacher presence" (Garrison and Anderson, 2003) in online learning and media use, but possibly also pointing to the effort and new learning needed to take on this role.

\section{Extending the range of the learning environment}

The second reason, that social media use extends the range of contacts, contexts, and resources for the learning environment, is stressed in research and thought collected under the term networked learning, an area focused on how information and communications technologies (ICTs) can be harnessed for teaching and learning. This perspective is particularly motivated by the opportunities ICTs provide for making connections among learners, teachers and learners, communities, and learning resources (Jones, 2015). Distributed, networked learners are also communityembedded learners, engaging with the combined set of local, online, and distance communities of their own and of others, bringing knowledge from the in-class experience to local others and bringing local knowledge to the class (Kazmer, 2007). The relatively new perspective of connectivism (Downes, 2012; Siemens, 2005) is also concerned with making connections, but adds to the human connectivity the importance of connecting with and across resources, sites, and media.

Beyond the work supporting the perspectives just noted, specific studies of social media use for extending the range of learning experiences are limited. Among the few actual studies, Lapolla (2014) evaluated the use of Pinterest in a fashion design course, finding that students felt they benefited from the ability to communicate with customers via this medium. Extension is mentioned as an intent for using social media. For example, Lupton (2014) reports that respondents on her survey indicated engaging with others in the class and with external learning communities as one reason for using social media, and extending class contact time as another reason, including the ability for quick response. Extension of class contact venues is another reason for social media use. Manca and Ranieri (2013) reviewed studies that explored the use of Facebook for learning and found it was used as a replacement for the Learning Management System (LMS) and as another closed venue for sharing information and engaging in discussion within a cohort of students.

\section{Promoting learning through social interaction and collaboration}

The third potential reason for using social media in teaching is to promote a social, collaborative approach to learning and greater reflection. This resonates with the perspectives of networked learning, connectivism, and knowledgebuilding communities discussed above. Connection among learners and actors in the learning environment is emphasized in the perspectives of collaborative learning (Bruffee, 1993), computer-supported collaborative learning (Miyake, 2007), and social network analytic perspectives on learning (Haythornthwaite, de Laat \& Schreurs, 2016). 
Starting with Vygotsky's (1978) constructivist ideas, these perspectives acknowledge and build on the way individual knowledge acquisition and production benefit from interaction between people. Of note here is that the teacher is not a forgotten actor, but remains an important interactant. Vygotsky saw the importance of teachers as aiding learners in the zone of proximal development, the difference between what they could achieve without help and what they could achieve with help. Garrison and Anderson (2003) argue for teacher presence as one of three essential aspects in online learning, along with social presence and cognitive presence.

Each of these perspectives on making connections includes a tacit or explicit assumption of activity on the part of teachers and/or of learners. In this, we see the expectation of engagement and reflection that becomes one of the reasons for using social media in teaching. Learners need to bring cognitive presence, engage with others, and learn and practice new norms. Learners need to be active in constructing their own learning environments of people, information, and connections, which also signals a contemporary need to understand the multiple sources and influences on one's own personal learning environments (Luckin, 2010). Use of social media in teaching thus exposes participants to the culture of active participation, sharing, openness, and collaboration while also engaging learners in the active, even entrepreneurial (Senges et al., 2008), pursuit and management of their own personal learning (Haythornthwaite et al., 2016).

By contrast with the other suggested reasons for using social media in teaching, there are more studies on social media and use for interaction with others in support of engagement, reflection, and community building. Educators both expect and are finding positive learning outcomes relating to learner engagement resulting from social media use. Brown (2012) finds, from a study of perceptions of usefulness of social media for teaching, that faculty see the potential of social media as being able to promote active participation in the learning process, as well as to disseminate information. Junco et al. (2011) compared results from two groups in one class, one group using Twitter for class (70 of 125 students) and one group not using Twitter for class (55 students). Pre- and post-test results on the 19-point National Survey of Student Engagement scale showed significantly higher engagement among members of the Twitter-using group than the comparison group and significantly higher grade point averages. An analysis of the Twitter posts showed that both instructors and students were highly engaged in ways not associated with typical classroom interactions. For example, there were demonstrations of social and emotional support that were unexpected by the authors, but can also be seen as important markers for community building (Haythornthwaite, 2007). Similarly, a study by Deng and Yuen (2011) also showed that social support emerges in these environments; while exploring the educational affordances of blogs, theirstudy found that commenting on blogs tended to create a focus on social support. In addition to discovering that community is emerging, deliberately building community is often an identified goal of using social media, following on much of the e-learning research that has emphasized the development of learning communities (Falk and Drayton, 2010).

\section{Applying the U\&G framework}

These three general reasons just discussed for why instructors may seek to introduce social media are derived from theoretical perspectives relating to teaching and learning, and particularly from literature on new media and online or e-learning. However, decision-making in an institutional context also grapples with the requirements of the day-today operation of teaching practice, administrative responsibilities relating to teaching, and organizational contexts. Thus, reasons may emerge that are unrelated to theoretical positions about teaching. Furthermore, in an age of participatory media and the context of social media, choices and actions are not just about what media will be consulted for information but also which media will receive contributions (see also Papacharissi, 2008). Seaman and Tinti-Kane (2013) open up this kind of inquiry when they asked survey respondents what they asked students to do with the media for assignments: read, watch, listen, add comment, or create. Not surprisingly, intent varied by medium, with higher creation and comment as requirement for blogs and wikis, and higher listening for podcasts. This kind of exploration opens up questions of how individual media are selected and applied by instructors for the separate or dual purposes of retrieval and production of knowledge and encourages a more nuanced look at media use than a blanket assessment of "social media" as one concept.

For these reasons, the U\&G framework suits our research because it does not assume a pre-defined set of motivational factors, but instead lets factors emerge from data; it leads us to ask how and why such media are adopted, and how each serves the purposes of the individual adopters. This suits our case because we are specifically focusing on a group of instructors (likely early adopters) who are already using social media in their classes (see also Smith, 2014). To learn more about on what individuals were doing with the media in the context of teaching and why, as well as gathering data on what media are used by faculty in general and for teaching, our study included two open-ended questions about how social media were used in their teaching. Answers to these questions allow factors to emerge from the data. 
This study builds on the work of Quan-Haase et al. (2015) and Gruzd and Goertzen (2013) where reviews of earlier work may be found, which applied the U\&G framework to study how scholars in different fields use social media for research, communication, collaboration, and information purposes. This work also extends U\&G research by looking not at any one particular social networking platform but at a wide variety of platforms and with the focus on use for teaching. While the U\&G framework has been criticized for its tendency to produce over-generalized models (Sundar and Limperos, 2013), this concern is addressed here by developing a very granular scale of reasons explaining social media use by instructors, and, in order to get a fuller picture, applying a factor analysis to identify how these unique reasons might relate to each other.

\section{Research questions}

This background, theoretical framing, and the increasing societal presence and use of social media led us to frame these questions for this article: What media are instructors in higher education using in their teaching? What media are found to be most useful, and why? And, how do these reasons for use relate to each other? In exploring these questions, we are interested in understanding how media are brought into the lives of instructors and the practice of teaching, with what intent, and with what success.

\section{Method and sample Questionnaire}

The questionnaire used in this study was designed to shed light on university instructors' use of social media in their teaching. The survey consisted of 27 questions in two main parts, with some questions having multiple options to choose from (e.g. which of the following media have you used?). The first part asked for general information about use of social media and use in any aspect of their teaching; the second part asked participants to consider a particular course, taught either online or face-to-face, and to answer questions about social media use in that course. This was followed by questions asking about the demographics of their institution and themselves.

The questionnaire was developed and piloted in 2013-2014, and institutional ethics review was obtained for the conduct of this study. Participants participated in the study anonymously, but had the option at the end to exit the survey and enter their email address in order to be entered in a draw for an iPad. Email data were stored separately from the questionnaire data and deleted after the draw. The questionnaire was implemented and hosted through the web survey company Qualtrics (http://www.qualtrics.com), through a license at the hosting university, with responses stored on their servers located in Ireland.

The final version was made public in March 2014 and remained open to contribution until February 2015 in order to obtain as many responses as possible. Recruitment was undertaken through disseminating notice of the research and the opportunity to participate through a variety of means, including personal emails to known or recommended contacts, email to academic mailing lists, distribution of information at conferences and at presentations, by mention and by distribution of study "business cards" that gave survey and site information, and Twitter postings to relevant conference hashtags. Participation was encouraged from any and all instructors in higher education, regardless of rank or academic status, and from any country or region.

Table 1. Respondent demographics (questionnaire parts 1 and 2).

\begin{tabular}{|c|c|c|c|}
\hline Gender & Age & Country & Institution \\
\hline 229 responses & 219 responses & 230 responses & 230 responses \\
\hline $61 \%$-Women & $49 \%-25-40$ & 45\%-UUnited States & $49 \%$-Granting masters and doctoral \\
\hline \multirow{5}{*}{ 39\%-Men } & $42 \%-41-60$ & $20 \%$-Canada & degrees \\
\hline & $9 \%-61-79$ & $6 \%$-Australia & $44 \%$-Primarily undergraduate \\
\hline & & $6 \%$-United Kingdom & institutions \\
\hline & & $3 \%$-Germany & $4 \%$-Only masters degrees \\
\hline & & $\begin{array}{l}3 \% \text {-Brazil } \\
+ \text { Other countries }\end{array}$ & $\begin{array}{l}3 \%-2-y e a r \text { institutions or community } \\
\text { colleges }\end{array}$ \\
\hline
\end{tabular}


Table 2. Questionnaire demographics (questionnaire part 2 only).

\begin{tabular}{|c|c|c|c|c|}
\hline \multirow{13}{*}{$\begin{array}{l}\text { Gender } \\
173 \text { responses } \\
61 \% \text {-Women } \\
39 \% \text {-Men }\end{array}$} & Age & Country & Institution & Course discipline \\
\hline & 165 responses & 174 responses & 176 responses & 180 responses \\
\hline & $48 \%-25-40$ & $50 \%$-United States & $49 \%$ - Granting masters and & $19 \%$-Journalism, \\
\hline & $44 \%-41-60$ & $18 \%$-Canada & doctoral degrees & Media Studies and \\
\hline & $8 \%-61-79$ & $6 \%$-Australia & $44 \%$-Primarily undergraduate & Communication \\
\hline & & $5 \%$-United Kingdom & institutions & $9 \%$-Information \\
\hline & & $4 \%$-Germany & $4 \%$-Only masters degrees & Science \\
\hline & & 3\%-Brazil & $3 \%-2$-year institutions or & $8 \%$-Education \\
\hline & & + Other countries & community colleges & $8 \%$-Computer \\
\hline & & & & Sciences \\
\hline & & & & $6 \%$-Sociology \\
\hline & & & & 6\%-Social Sciences \\
\hline & & & & + Other disciplines \\
\hline
\end{tabular}

\section{Respondent demographics}

In total, 417 participants started the questionnaire, but 84 did not answer any questions or answered fewer than 10 questions or subparts of questions; our data also showed that these individuals spent less than 1 minute on the questionnaire. Hence, the responses of a total of 333 participants were used in our analyses. Part 2 of questionnaire was presented as optional since it required extra time and qualitative answers: 210 participants provided information in this section. Tables 1 and 2 present the reported demographic information of the study participants.

\section{Results}

\section{Social media use in teaching}

First, respondents were asked about which social media they used in teaching. The options and the number of participants indicating they presently used these social media in teaching are shown in Figure 1 . Of interest is whether the tools used were those provided by and/or integrated with the institutional LMS. It is quite clear that there is far greater use of social media tools from outside the LMS rather than inside, with the marked exception of asynchronous discussion.

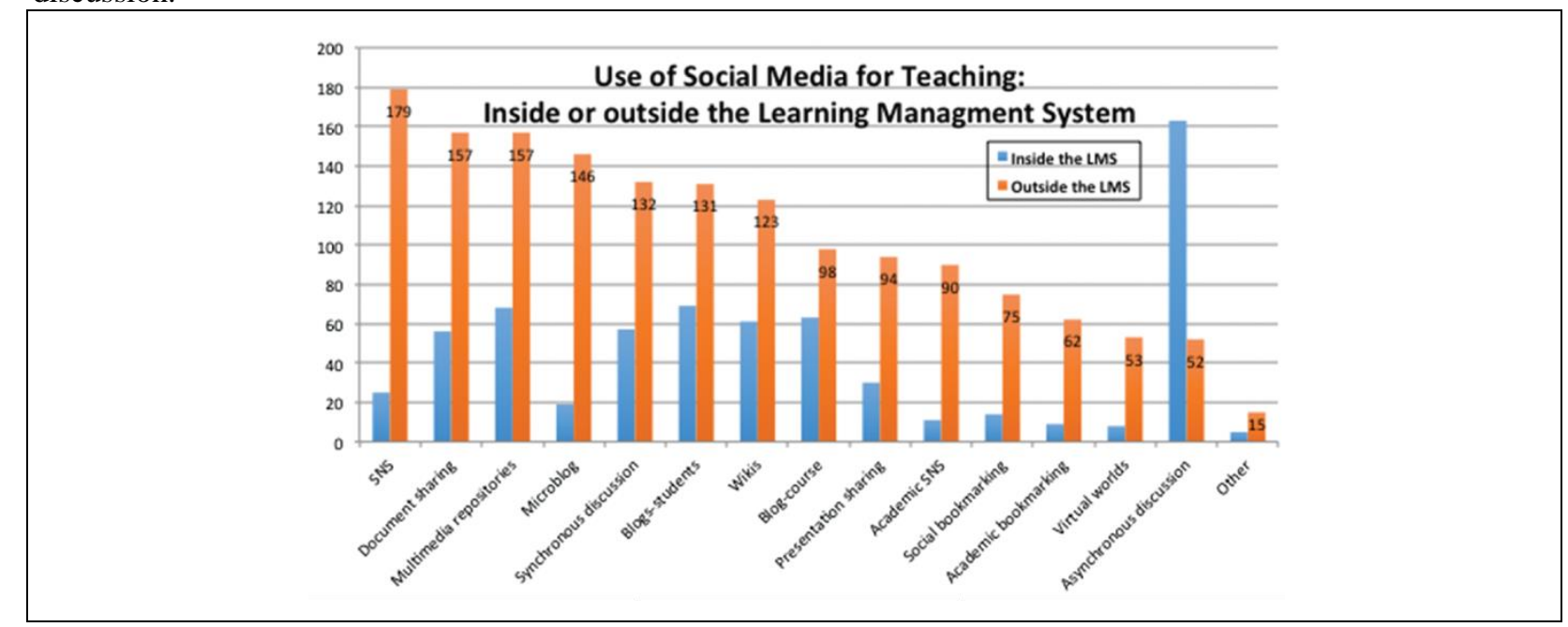

Figure 1. Use of social media inside and outside the LMS.

Table 3. Most useful social media tool for teaching.

\begin{tabular}{ll}
\hline Social media tool & Number of respondents who indicated the tool as most useful \\
\hline Blog/Wordpress & 64 \\
Twitter & 47 \\
YouTube & 32 \\
Facebook & 26 \\
\hline
\end{tabular}




\begin{tabular}{ll}
\hline Document sharing/sharing/Google docs & 23 \\
Discussion/forum & 22 \\
Wiki & 16
\end{tabular}

For the purposes of coding, "discussion" and "forums" were counted once if appearing together in an answer, combined for either word in the total; similarly "blog" and "Wordpress", and "Document sharing" and "Google docs" were combined.

\section{Most useful social media tool}

Table 3 presents results from the question "What is the most useful social media tool you have used for teaching?" Open-ended answers are summarized based on matching words in the answers to media types and brands. In total, 239 nominations of specific tools were given. If two types of tools were indicated, both were counted (although most answers indicated only one tool as "most useful"); six respondents indicated "many" social media tools were useful but did not name a specific tool; five indicated "no" useful tool; and the remaining respondents provided no answer.

Blogs in general (including Wordpress), Twitter microblogging, YouTube videos, Facebook social networking site, document sharing (including "sharing" and Google docs), and discussion forums top the list of most useful media, with wikis. Of most interest is what made these media "most useful"; this is taken up below in the analysis of instructor's answers to two open-ended questions about their use of these media in teaching.

\section{Social media use in teaching}

The second part of the questionnaire was designed to solicit further details on social media in teaching by asking respondents to answer about use in one specific course. This section was aimed at gathering actual experiences in teaching settings, both the pros and cons, and participants' reflections on usefulness in supporting their teaching goals. This section required a lot of descriptive and thoughtful textual responses from participants and was presented as optional to participants; 210 respondents gave answers in this section. Those who opted not to complete this section moved directly on to demographic questions.

Of particular interest for this research is how instructors are using social media in teaching. To that end, we concentrated our examination on answers to two questions on this topic. Following the question of "What is the most useful social media tool you have used for teaching?", participants were asked to "give a brief explanation of how you use the above tool in your course(s)." In addition to this question, participants were also asked to "consider one specific course you have recently taught where you used any social media tool for teaching" and to answer "How have you used social media in this course?"

Qualitative coding. To analyze the answers to these two questions, a content analysis was performed to code the responses. One of the authors created the codes, which were then evaluated by two other authors to reach agreement; the coding scheme fit both questions. Two authors then coded responses on each of the two questions with a third author reconciling differences. Participants' answers could have more than one code and often did. Participants also indicated whether they gave permission for qualitative answers to be quoted; only comments from those so indicating are used here.

The following describes the codes. Note that all answers are given by the instructor about their intended purpose for use of social media in teaching. For a number of codes, there were implementations for the instructor's practice (marked with a numerical code "1") and implementations for the student's practice (marked with a numerical code “2”). Where this applies, codes were subdivided by directionality, for example, organizing (O) could have been by the instructor for the instructor's practice $(\mathrm{O} 1)$ or it could be organizing by instructors to facilitate student practice (O2).

Sharing (S1 and S2) was assigned where social media were used to post content (e.g. information sources and resources, including sources created by students). The tool could be used to share content by instructors for personal use or for students, or could be shared by students for personal use or for other students. Content was shared via social media by instructors to students (S1) or to facilitate content sharing by students (S2). Discussing (DC) was applied as an in vivo code where the word discussing or a variant appeared and indicated using social media to provide a forum through which to discuss course-based topics. Organizing $(\mathrm{O} 1$ and $\mathrm{O} 2)$ indicated that social media were used to facilitate the organization of the course for the instructor $(\mathrm{O} 1)$ or by the instructor to facilitate organization for the students (O2). This code includes course-wide organization, such as using the tool for submission of and feedback on assignments or other coursework, and personal organization such as collecting or annotating sources.

The following codes all refer to deliberate and intentional use of social media to effect certain pedagogical outcomes. The code Reflective learning (RL) was applied where social media were used to create a means for students to reflect on their work and/or progress. Peer interaction (PI) indicated use to enhance student-to-student interaction 
relating to each other's work and to foster peer-to-peer instruction and learning. Common examples include editing each other's work or providing feedback on each other's work. Supporting collaboration (SC) indicated use to provide students with a means of working together on shared projects. Reaching outside the class (RO) was applied where the comment indicated the intent to provide learning experiences outside the classroom setting, for example, creating networks between students and the professional community. Learning about social media use through practice (LP) was applied where social media were employed with the intent of providing students with practical experience using social media tools.

The code Discovering (D1 and D2) was applied where use of social media allowed discovery of relevant information resources either used by instructors to discover information (D1) or used by instructors to help students to discover information (D2). Fostering the learning community (FC) was applied as a code where comments indicated the use of social media helped to foster community development among learners.

Table 4 shows the prevalence of these codes for each question. Sharing, discussing, organizing by the instructor, and reflective learning were most common, followed by supporting collaboration, reaching outside the class, learning through practice, and discovery and organizing by students. Less frequently reported was fostering the learning community, and only a few instances reflected discovery by instructor.

Factor analysis. To gain further insight into approaches to using social media in teaching, the coded responses were further analyzed using a factor analysis. This analysis identifies clusters of codes that occur together and further explains instructors' approaches to the use of social media. Data for the analysis are the codes assigned to the two open-ended questions described above. The data derived from the codification process were transformed into binary variables for the analysis and a factor analysis run on the joint set of codes assigned to respondents' answers. Both of these questions capture aspects of reasons and applications for use of social media in teaching, and joining the answers provided a larger dataset of comments for analysis.

A principal component factor analysis (with varimax rotation and Kaiser normalization) was used to identify clusters of usages of social media for teaching. Prior to analysis, we first confirmed that there are no multicollinearity problems between variables (no correlation coefficients above .9, determinant of the correlation matrix: .460). We also confirmed that our data meet the minimum standard to perform a factor analysis: (1) the value of Kaiser-MeyerOlkin measure of sampling adequacy is at least .6 (Field, 2009), which in our case is .618, and (2) Bartlett's test of sphericity is significant (in our case, $p<.000$ ).

The analysis suggested six factors relating to instructors' use of social media for teaching (see Table 5). The total variance explained by the six factors is $59.56 \%$, with variance explained per factor of 12.63 (Factor 1) to 8.48 (Factor 6) (see Table 5). Interpreting these results suggests that reasons for instructors' use of social media for teaching relate to (1) facilitating student engagement, (2) instructor's organization for teaching, (3) engagement with outside resources, (4) enhancing student attention to content, (5) building communities of practice through use of social media, and (6) resource discovery. A detailed interpretation of each factor is provided below.

Table 4. Distribution of codes about how social media were used in teaching.

\begin{tabular}{llll}
\hline Code & & $\begin{array}{l}\text { How the "most useful social } \\
\text { media tool" was used in their } \\
\text { courses(s) }\end{array}$ & $\begin{array}{l}\text { How social media was used in } \\
\text { one specific recently taught } \\
\text { class }^{\text {b }}\end{array}$ \\
\hline S2 & Sharing among students & 59 & 41 \\
DC & Discussing & 50 & 42 \\
S1 & Sharing by instructor & 46 & 41 \\
O1 & Organizing for instructor & 41 & 29 \\
RL & Reflective learning & 36 & 21 \\
PI & Peer interaction & 23 & 11 \\
SC & Supporting collaboration & 18 & 8 \\
RO & Reaching outside the class & 16 & 3 \\
LP & Learning about SM through practice & 15 & 16 \\
D2 & Discovery by students & 14 & 7 \\
O2 & Organizing for students & 12 & 5 \\
FC & Fostering the learning community & 9 & 9 \\
D1 & Discovery by instructor & 3 & 1 \\
\hline SM: & & &
\end{tabular}

SM: social media.

a 4 responses could not be interpreted for coding.

b27 responses could not be interpreted for coding. 
Table 5. Factor analysis of uses of social media in teaching.

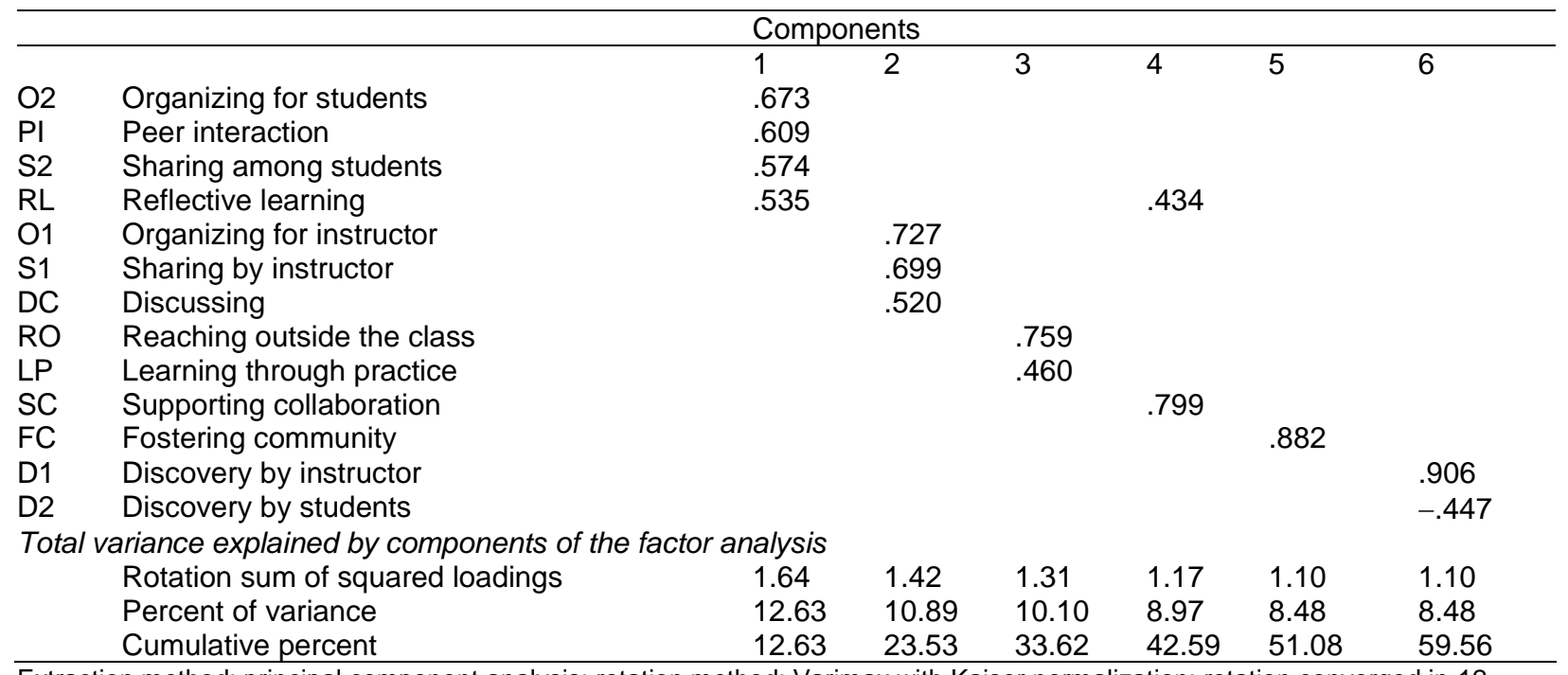

Extraction method: principal component analysis; rotation method: Varimax with Kaiser normalization; rotation converged in 12 iterations.

Factor 1: Facilitating Engagement entails uses for teaching that are all oriented to facilitating student participation, interaction, and reflection: O2: Organizing for students; PI: Peer interaction; S2: Sharing among students; and RL: Reflective learning. This factor brings together a set of instructors whose motivations for using social media in classes are to enhance student learning behaviors.

Factor 2: Organization for Teaching comprised uses oriented to facilitating the organization of the activity of teaching, including course organizing, dissemination of content, and organizing interaction through discussion: O1: Organizing for instructor; S1: Sharing by instructor; and DC: Discussing. This indicates a set of instructors whose use of social media in classes is directed to management of teaching practice.

Factor 3: Reaching Outside suggests a set of instructors who use social media to connect the class experience to the knowledge and work worlds: RO: Reaching outside the class and LP: Learning through practice. The "reaching outside" code was applied for comments that indicated use of resources beyond the institution or classroom, for example, open online resources, news, and so on. "Learning by practice" captured in-class use that was a way of learning how to use social media for work and communication outside educational use.

Factor 4: Enhancing Student Learning includes RL: Reflective learning and SC: Supporting collaboration. At first hard to interpret, a review of the comments coded as both supporting collaboration and reflective learning showed they often include a reference to group work and a group way into reflection. Thus, it suggests this factor shows social media are used to move the locus of action from the teacher-student relationship to the student and student-student relationship, and in both cases for reflection and further engagement with the course materials. To some extent, this also suggests a private to public crossover, for example, from the private student reflection to making that reflection public in groups.

Factor 5: Building a Community of Practice rests on one code only: FC: Fostering community. The code was assigned either because of a direct reference by the respondent that they were using social media to foster community or by interpretation of the coders that the response suggested an all-inclusive approach to use of social media, with participants specifying multiple uses and ways of engagement and/or included comment about facilitating group projects. Responses that were interpreted as fostering community were often much longer answers to the questions about social media use. Overall, this factor seemed to address building communities of practice through use of social media.

Factor 6: Discovery we interpret with caution due to the negative value for discovery by students and the few cases for discovery by instructors: D1: Discovery by instructor and D2: Discovery by students. Those who indicated they used social media for their own discovery of information appear to not use it to boost students' capacities to reach new outside information. Our cautious interpretation is that it is related to the locus of control for information gatekeeping, either maintained by the instructor (e.g. "I essentially run across resources that I bring into the f2f [faceto-face] classroom") or granted to the students (e.g. "Had students connect with each other and find information about topics relevant to course material to share inside and outside class"). 


\section{Discussion}

At the start, we proposed three main reasons for faculty to include social media use in teaching suggested by education and learning theories: (1) exposing students to practices, (2) extending the range of the learning environment, and (3) promoting learning through social interaction and collaboration. With the help of the U\&G perspective and a factor analysis, we derived six factors from instructors' reports on their actual use of social media for teaching. The resulting six factors generally align well with the three reasons proposed and also introduce other aspects of social media use related to the organization of teaching.

The first reason, exposing students to practices, is reflected in Factor 3: Reaching Outside. Because this factor was not limited to outreach to resources and also included learning the practices of social media use, we can say that participants in our study used social media to expose students to resources and practices outside the traditional classroom setting. This is in keeping with pedagogical ideas of experiential learning and Dewey's theoretical principles of learning through the "lived experience." As previous work suggests, connecting activities to the outside world and to current practices is an important way to enhance learners' understanding of new concepts and ideas (Bruce, 2009).

The second reason, extending the range of the learning environment, is reflected in Factor 6: Discovery. Although we remain cautious about this factor, we can say that here social media were used to extend learners and instructors' ability to locate and access new resources and information outside their learning environment. This could be by means of various targeted and/or serendipitous linkages that may appear in social media posts, as well as through social interactions with peer learners and others outside the class. We see this capacity of social media to help learners connect and discover new resources and information as representing a key facilitating factor in what contemporary scholars refer to as connectivism, networked learning, and community-embedded learning (Jones, 2015; Kazmer, 2007; Siemens, 2005).

The third reason that emerged from the literature, promoting learning through social interaction and collaboration, and its corollary of gaining greater student reflection, appears in three factors: Factor 1: Facilitating Engagement; Factor 4: Enhancing Student Learning; and Factor 5: Building a Community of Practice. Together these factors speak to instructors' use of social media to support collaborative learning (Bruffee, 1993) and to take advantage in their pedagogy of the value of social connections among learners (Haythornthwaite and Andrews, 2011; Haythornthwaite et al., 2016). Such use of social media can be broadly referred to as computer-supported collaborative learning (Miyake, 2007), with roots in Vygotsky's (1978) ideas that learning is co-constructed through social interactions with others.

In addition to identifying and mapping the factors to the three reasons suggested by education and learning theories, our research identified the additional Factor 2: Organization for Teaching. This factor accords with the theoretical perspective of the active media user from the $U \& G$ framework. This active user selects media and shapes use to their own purposes, here the purpose of managing and conducting classes. This active choice is also evident in the way these respondents overwhelmingly choose social media from outside the provided LMS options, reflecting their active seeking for media to support their teaching purposes.

The emergence of a factor directly related to the organization of teaching is a significant discovery because none of the known studies in this area point to such usage. It was initially assumed that social media use in the classroom would be directly related to student activities. But this factor shows that an important aspect of social media use by instructors is related to their use in the context of teaching. Another reason this factor is important is that it signifies how the totality of the teaching work environment becomes part of the social media use landscape. Use is not isolated to just connecting to external resources, to just gaining experience with social media use, or to just supporting peerto-peer interaction, but instead includes the totality of organizing, communicating, accessing resources, and connecting with students. It signifies the importance of understanding the full range of activities involved when examining social media use whether in teaching or other contexts (see also Gruzd and Haythornthwaite, 2013; Haythornthwaite, 2002, 2007).

\section{Conclusion}

This research examined which social media were used in teaching, and how they were used, by a sample of active social media users. Results revealed the most popular social media platforms used for teaching by these respondents were blogs, microblogging, video sharing via YouTube, social networking via Facebook, and document sharing (including Google Docs). Usage patterns for teaching were associated with six distinct factors: (1) facilitating student engagement, (2) instructor's organization for teaching, (3) engagement with outside resources, (4) enhancing student attention to content, (5) building communities of practice, and (6) resource discovery. These factors align with three 
main reasons for use of social media in teaching suggested by education and learning theories: (1) exposing students to practices, (2) extending the range of the learning environment, and (3) promoting learning through social interaction and collaboration, and revealed another, unexpected aspect of social media use: (4) use by instructors for organizing their teaching. Together these factors provide a more comprehensive picture of social media use than provided by previous work, encompassing not only the array of media used but also the range of purposes associated with contemporary teaching.

Two limitations exist for our research. The non-representative sample limits the ability to make generalizations to a wider range of instructors. In particular, our study participants consisted of instructors who are likely to be more active social media users than those in the general population due both to interest in the topic and our recruiting methods (e.g., notification of the study through Twitter). Nevertheless, we believe this research offers a solid foundation to those who are interested in exploring further the reasons for use of social media in higher education.

The findings from this study serve to inform several audiences. Considering that our study participants are likely to be early adopters of these technologies, the findings can be used as a roadmap for other instructors who are beginning to consider the use of social media in their classes. Our research also showed that most of the instructors use social media tools outside the LMS; thus, LMS developers can use the resulting factors as guiding principles for better integration of social media functionalities and external social media platforms into existing LMS platforms. For researchers, the factors identified in our work, and the application of the U\&G framework in this study, can be used as a starting point and a comparative case for other researchers when applying the framework to discover factors that drive the adoption and use of a social media in educational or other settings.

\section{Funding}

This research is supported through a five-year research initiative (2013-2018) "Learning Analytics for the Social Media Age" funded by the Social Science and Humanities Research Council of Canada, PIs Anatoliy Gruzd and Caroline Haythornthwaite.

\section{References}

Bandura A (2001) Social cognitive theory: an agentive perspective. Annual Review of Psychology 52: 1-26.

Bennett S, Bishop A, Dalgarno B, et al. (2012) Implementing Web 2.0 technologies in higher education: a collective case study. Computers \& Education 59: 524-534.

Brown SA (2012) Seeing Web 2.0 in context: a study of academic perceptions. The Internet and Higher Education 15(1): 50-57.

Bruce BC (2009) Ubiquitous learning, ubiquitous computing, and lived experience. In: Cope B and Kalantzis M (eds) Ubiquitous Learning. Champaign, IL: University of Illinois Press, pp. 21-30.

Bruffee KA (1993) Collaborative Learning: Higher Education, Interdependence, and the Authority of Knowledge. Baltimore, MD: Johns Hopkins University Press.

Dahlstrom E, Walker JD and Dziuban C (2013) Educause centre for analytics and research (ECAR) study of undergraduate students and information technology, 2013. Available at: http://www.educause.edu/library/resources/ecar-study-undergraduatestudents-and-information-technology-2013

Davis JL, Compton DL, Farris DN, et al. (2015) Implementing and analyzing social media in higher education. Journal of Faculty Development 29(2): 9-16.

Deng L and Yuen AH (2011) Towards a framework for educational affordances of blogs. Computers \& Education 56(2), $441-451$.

Dewey J (1930) Democracy and Education: An Introduction to the Philosophy of Education. New York: MacMillan.

Downes S (2012) Connectivism and connective knowledge: essays on meaning and learning networks. Available at: http://www.downes.ca/files/books/Connective_Knowledge-19May2012.pdf

Field A (2009) Discovering Statistics Using SPSS: Third Edition. London: SAGE.

Falk JK and Drayton B (eds) (2010) Creating and Sustaining Online Professional Learning Communities. New York: Teachers College Press.

Gammon MA and McGranahan C (2015) Theory through application: a study in the use of social media for teaching. Journal of Faculty Development 29(2): 23-32.

Garrison DR and Anderson T (2003) E-learning in the 21st Century: A Framework for Research and Practice. Falmer: Routledge.

Gruzd A and Goertzen M (2013) Wired academia: why social science scholars are using social media. In: Proceedings of the 46th Hawaii international conference on systems sciences, Wailea, 7-10 January 2013, pp. 3332-3341.

Gruzd A and Haythornthwaite C (2013) Enabling community through social media. Journal of Medical Internet Research 15(10): e248.

Haythornthwaite C (2002) Building social networks via computer networks: creating and sustaining distributed learning communities. In: Renninger KA and Shumar W (eds) Building Virtual Communities: Learning and Change in Cyberspace. Cambridge: Cambridge University Press, pp. 159-190. 
Haythornthwaite C (2007) Social networks and online community. In: Joinson A, McKenna K, Reips U, et al. (eds) Oxford Handbook of Internet Psychology. Oxford: Oxford University Press, pp. 121-136.

Haythornthwaite C and Andrews R (2011) E-learning Theory and Practice. Thousand Oaks, CA: SAGE.

Haythornthwaite C, De Laat M and Schreurs B (2016) Social network analytic perspective on learning. In: Haythornthwaite C, Andrews R, Fransman J, et al. (eds) SAGE Handbook of E-Learning Research. 2nd ed. London: SAGE.

Hung H and Yuen S (2010) Educational use of social networking technology in higher education. Teaching in Higher Education 15(6): 703-714.

Imlawi J, Gregg D and Karimi J (2015) Student engagement in course-based social networks: the impact of instructor credibility and use of communication. Computers \& Education 88: 84-96.

Jones C (2015) Networked Learning: An Educational Paradigm for the Age of Digital Networks. London: Springer.

Junco R, Heiberger G and Loken E (2011) The effect of twitter on college student engagement and grades. Journal of Computer Assisted Learning 27(2): 119-132.

Katz E, Blumler JG and Gurevitch M (1973) Uses and gratifications research. Public Opinion Quarterly 37(4): 509-523.

Kazmer MM (2007) Community-embedded learning. In: Andrews R and Haythornthwaite C (eds) Handbook of E-learning Research. London: SAGE, pp. 311-327.

Lampe C, Wohn DY, Vitak J, et al. (2011) Student use of Facebook for organizing collaborative classroom activities. International Journal of Computer-Supported Collaborative Learning 6(3): 329-347.

Lapolla K (2014) The Pinterest project: using social media in an undergraduate second year fashion design course at a United States University. Art, Design and Communication in Higher Education 13(2): 175-187.

Lave J and Wenger E (1991) Situated Learning: Legitimate Peripheral Participation. Cambridge: Cambridge University Press

Luckin R (2010) Re-designing Learning Contexts: Technology-rich, Learner-centred Ecologies. Abingdon, UK: Routledge.

Lupton D (2014) "Feeling better connected": academics' use of social media. Available at: http://www.canberra.edu.au/aboutuc/faculties/arts-design/attachments2/pdf/n-and-mrc/Feeling-Better-Connected-report-final.pdf

Manca S and Ranieri M (2013) Is it a tool suitable for learning? A critical review of the literature on Facebook as a technologyenhanced learning environment. Journal of Computer Assisted Learning 29(6): 487-504.

Manca S and Ranieri M (2016) "Yes for sharing, no for teaching!": social media in academic practices. The Internet and Higher Education 29: 63-74.

Miyake N (2007) Computer supported collaborative learning. In: Andrews R and Haythornthwaite C (eds) Handbook of E-learning Research. London: SAGE, pp. 263-280.

Papacharissi Z (2008) Uses and gratifications. In: Salwen M and Stacks C (eds) An Integrated Approach to Communication Theory and Research. New York: Lawrence Erlbaum, pp. 137-152.

Perrin A (2015) Social media usage: 2005-2015. Available at: http://www.pewinternet.org/ 2015/10/08/social-netwrking-usage-2005-2015

Quan-Haase A, Martin K and McCay-Peet L (2015) Networks of digital humanities scholars: the informational and social uses and gratifications of Twitter. Big Data \& Society 2(1): 1-12.

Seaman J and Tinti-Kane H (2013) Social media for teaching and learning. Available at: http://www.pearsonlearningsolutions.com/higher-education/social-media-survey.php

Senges M, Brown JS and Rheingold H (2008) Entrepreneurial learning in the networked age. How new learning environments foster entrepreneurship and innovation. Paradigms 1(1): 125-140.

Shao G (2009) Understanding the appeal of user-generated media: a uses and gratification perspective. Internet Research 19(1): 725.

Siemens G (2005) Connectivism: a learning theory for the digital age. International Journal of Instructional Technology and Distance Learning 2(1): 3-10.

Smith, D. (2014). Faculty leadership behaviors and the adoption of social media. Doctoral Dissertation, Dallas Baptist University. Available from ProQuest Dissertations \& Theses Global database. (Order Number 3646795).

Sundar SS and Limperos AM (2013) Uses and grats 2.0: new gratifications for new media. Journal of Broadcasting \& Electronic Media 57(4): 504-525.

Veletsianos G, Kimmons R and French KD (2013) Instructor experiences with a social networking site in a higher education setting: expectations, frustrations, appropriation, and compartmentalization. Educational Technology Research and Development 61(2): $255-278$.

Vygotsky L (1978) Mind in Society: The Development of Higher Psychological Processes. Cambridge, MA: Harvard University Press.

Waldeck JH and Dougherty K (2011) Collaborative communication technologies and learning in college courses: which are used, for what purposes, and to what ends? Learning, Media and Technology 37(4): 1-24. 